\title{
Consciência imaginativa, fantasia e método em Husserl
}

\section{Imaginative consciousness, phantasy and method in Husserl}

\section{Alberto Marcos Onate}

Doutor em Filosofia pela Universidade de São Paulo (USP), professor associado da Universidade Estadual do Oeste do Paraná (UNIOESTE), Toledo, PR - Brasil, e-mail: am.onate@uol.com.br

\section{Resumo}

Quando elabora a terceira seção de Idéias $I,{ }^{1}$ e em especial o parágrafo 70, Husserl lega a seus intérpretes uma difícil tarefa. Embora estudos já clássicos, como os de Eugen Fink e Maria Manuela Saraiva, tenham de algum modo tratado das implicações filosóficas da referida seção, novas abordagens parecem pertinentes. Sobretudo, após a publicação em 1980 do volume 23 da Husserliana, referente às presentificações intuitivas. $\mathrm{O}$ artigo estrutura-se a partir de três objetivos nucleares: 1) expor e discutir os conceitos e argumentos decisivos da terceira seção de Idéias I, examinando a interpretação dos comentadores clássicos acima mencionados; 2)

1 Como a edição mencionada é anterior à reforma ortográfica da língua portuguesa, será mantida a grafia original, com acento. 
apresentar e debater as principais contribuições filosóficas trazidas pelo volume do Nachlass ao tratamento dos temas da consciência imaginativa, da ficção e do método fenomenológico husserliano, conectando-as à tessitura argumentativa dos referidos trechos de Idéias I; 3) examinar o alcance de algumas interpretações contemporâneas dos temas a partir do exposto nos itens anteriores.

Palavras-chave: Husserl. Fenomenologia. Consciência imaginativa. Fantasia. Método.

\section{Abstract}

When elaborating the third section of Ideas I, and in particular paragraph 70, Husserl hands down to its interpreters a difficult task. Although classic studies, such as of Eugen Fink and Maria Manuela Saraiva have somehow dealt with the philosophical implications of that section, new approaches are relevant. Especially after the publication in 1980 of volume 23 of Husserliana, referring to intuitive presentifications. The article is structured from three core objectives: 1) Explain and discuss the concepts and clinchers in the third section of Ideas I, examining the interpretation of the classic commentators mentioned above, 2) Present and discuss major philosophical contributions brought by the volume Nachlass of the treatment of the themes of imaginative consciousness, fiction and the Husserlian phenomenological method, connecting them to the argumentative texture of these pieces of Ideas I. 3) Examine the scope of some contemporary interpretations of the themes from the above in previous sections.

Keywords: Husserl. Phenomenology. Imaginative consciousness. Phantasy. Method.

\section{I}

Dentre os mais importantes legados cartesianos à fenomenologia de Husserl, destaca-se a preocupação com o método. Embora o pensador alemão condene os desvios naturalistas da trajetória cartesiana em busca do método perfeito para o conhecimento de tudo o que possa ser conhecido, conserva o modelo de um percurso metódico fundante, doravante conduzido em regime 
estritamente transcendental. A terceira seção do primeiro volume de Idéias para uma fenomenologia pura e para uma filosofia fenomenológica ${ }^{2}$ constitui um dos pontos altos da exposição husserliana respeitante ao método. O núcleo da seção parece estar na enigmática proposição que encerra o parágrafo 70 :

Assim, caso se goste de discursos paradoxais e se entenda a plurivocidade do sentido, pode-se efetivamente dizer, com estrita verdade, que a 'ficção' constitui o elemento vital da fenomenologia, bem como de todas as ciências eidéticas, que a ficção é a fonte da qual o conhecimento das 'verdades eternas' se alimenta (HUSSERL, 1976, p. 148). ${ }^{3}$

Para evitar mal-entendidos, Husserl logo acrescenta uma importante nota: "Uma proposição que, como citação, prestar-se-ia em especial para ridicularizar naturalmente o modo eidético de conhecimento" (HUSSERL, 1976, p. 148). Visando a escapar à cilada prevista pelo autor, cabe, primeiramente, analisar-se o contexto conceitual e argumentativo no qual se insere o trecho, para assim esclarecer o seu sentido e, sobretudo, as suas implicações filosóficas.

Conquistado o acesso ao campo transcendental, mediante progressivas reduções eidéticas e fenomenológicas, deve-se explorá-lo em sua infinidade, descrevendo com rigor o conjunto das vivências (Erlebnisse) puras e dos nexos essenciais que as entrelaçam. $\mathrm{O}$ maior desafio diz respeito ao começo correto, ao adequado ponto de partida das incursões transcendentais. As metodologias filosóficas e científicas pretéritas não servem de modelo, pois o âmbito a ser desbravado não fôra sequer vislumbrado por elas. A primeira dificuldade encontra-se na parentesiação do eu natural do próprio fenomenólogo que exercita o método. Embora Husserl se mostre confiante na consecução deste passo redutor, os pensadores da tradição fenomenológica comungarão na desconfiança quanto à exequibilidade de tal desconexão do processo aperceptivo natural, não sendo suficiente a exemplificação husserliana de que "o sujeito matemático, todavia, não pertence ao teor eidético das próprias proposições

2 Designado na sequência do texto como Idéias $I$.

3 Todas as traduções são de minha autoria, pois as opções terminológicas derivam da interpretação teórica adotada em cada caso. As traduções francesa, de Paul Ricoeur, e portuguesa, de Márcio Suzuki, vertem Phantasie por imagination e imaginação, respectivamente. Como se verificará ao longo do artigo, tal tradução não é adequada, pois pelo menos desde 1898 Husserl já estabelecia diferenças fenomenológicas decisivas entre Phantasie e Imagination, com todas as suas derivações vocabulares. 
matemáticas" (HUSSERL, 1976, p. 137). O eixo da argumentação husserliana contra seus futuros contestadores refere-se à harmonia de instauração intencional entre eu empírico e eu transcendental. Suas vigências intencionais são sucessivas, o que afasta o risco de exclusão de um pelo outro ou vice-versa. Ao invés de oposição devida a qualquer simultaneidade efetivadora, impera a plena complementaridade entre seus regimes intencionais alternadamente emergentes. Deve-se distinguir a concomitância no plano estritamente constitutivo, em que ambos se mostram contemporâneos, e a sucessividade dinâmica da atenção intencional que os apreende a cada vez. A segmentação decorre da atitude (Einstellung) assumida pelo eu na apreensão do campo fenomenal que se lhe apresenta: ora a atitude natural, interessada, entregue aos fenômenos; ora a atitude transcendental, desinteressada, reflexiva diante dos fenômenos. No limite, não há dois eus, mas apenas um eu que se desdobra visando a compreender as estruturas instauradoras dos fenômenos. Tal desdobramento egoico suspende a crença existencial na experiência natural de si, abstém-se dela, não a nega nem a coloca em dúvida e, justo nesta medida, é metodologicamente legítimo e filosoficamente fecundo. ${ }^{4}$

Considerando superado tal obstáculo metodológico, Husserl colocase de imediato perante outro óbice, ainda mais entranhado: agora não concernente ao estatuto do operador da fenomenologia, mas respeitante ao estatuto da relação da fenomenologia consigo. Enquanto investigação essencial das vivências puras, a visada fenomenológica depende, para instaurar-se metodologicamente, das próprias vivências puras que investiga, numa desconcertante autorremissão. Confluências que parecem encaminhar a um círculo metodológico. Embora reconheça certa dificuldade na solução do impasse, Husserl mostra-se confiante em sua explanação: o argumento-chave concerne à noção de aperfeiçoamento metódico, mediante o qual parte-se de incursões metodológicas hesitantes para, gradativamente, conquistar o pleno domínio metódico, propiciando que o autor diagnostique o alcance de seu próprio texto de maneira bastante favorável: "todo este escrito, que deseja preparar o caminho à fenomenologia, é, por seu conteúdo, integralmente fenomenologia" (HUSSERL, 1976, p. 139). Apesar do otimismo husserliano, deve-se encarar com seriedade os limites impostos pela autorremissão metodológica da fenomenologia, pois o recurso a noções como progressão concordante, ideia em

4 Nas Meditações cartesianas Husserl se expressa de maneira lapidar: "Com certeza pode-se dizer: eu, enquanto em atitude natural, sou também e sempre eu transcendental, mas só sei disto mediante o cumprimento da redução fenomenológica" (HUSSERL, 1973, p. 75).

Rev. Filos., Aurora, Curitiba, v. 22, n. 31, p. 347-378, jul./dez. 2010 
sentido kantiano, tarefa infinita e outras similares apenas procrastinam o veredito da fenomenologia sobre seu próprio alcance fundante, seja no tocante ao papel metódico da ficção, seja em relação a outros tópicos críticos. $\mathrm{O}$ desafio maior e global refere-se à passagem da atitude natural à atitude transcendental: se ela não se processa por um salto injustificado, como determinar, nas variadas etapas da modificação neutralizadora, o momento exato da transformação? Desafio que repercute diretamente na meditação e na exposição husserliana respeitantes ao privilégio metódico da ficção.

Outro cuidado metódico realçado por Husserl diz respeito à precisão na linguagem que expressa a apreensão de essências (Wesenserfassung). A exigência de univocidade terminológica está presente já nas Investigações lógicas e acompanha o pensador até em seus últimos textos públicos e privados. O discurso fenomenológico deve pautar-se exclusivamente por "significações claras e únicas" (HUSSERL, 1984, p. 140). Cumprir tal demanda implica, sobretudo, operar distinções vocabulares e proposicionais cada vez mais minuciosas, aptas a exprimir o exato contorno semântico e sintático de cada essência apreendida. Tanto nas obras publicadas quanto nos manuscritos particulares verifica-se o esmero husserliano na tarefa diferenciadora, embora nem sempre ela tenha cumprido seu escôpo. ${ }^{5}$ Se no discurso natural as equivocidades são inevitáveis, graças à contínua variação dos dados empíricos, o discurso transcendental requer já em sua instauração novas sintaxe e semântica. A opção husserliana para elaborá-las abdica do recurso a neologismos, mas, assim, obriga-se a explicar-se de modo reiterado sobre os novos significados, ajustados ao regime transcendental. As persistentes queixas pela incompreensão de seus leitores e críticos, as contínuas autocorreções expositivas, o emprego de um estilo denso e marcado por cadeias segmentadoras às vezes excessivas, decorrem desta escolha, talvez necessária, mas incômoda, inclusive para o autor. ${ }^{6}$

5 Ao longo de seu estudo sobre A imaginação segundo Husserl, Maria Manuela Saraiva aponta diversas lacunas nestas "distinções subtis e nem sempre claras" (SARAIVA, 1994, p. 149).

6 No prefácio de 1920 à Sexta Investigação Lógica, ele afirma: "Quem aqui, bem como nas Idéias, quiser entender o sentido das minhas exposições, não deve, com certeza, temer incômodos consideráveis, nem mesmo o incômodo de 'parentesiar' os seus próprios conceitos e convicções. Os incômodos, todavia, são exigidos pela natureza das coisas. Quem não os teme, encontrará ocasião bastante para aperfeiçoar as minhas exposições e, se tal lhe der prazer, censurar as suas imperfeições. Só não deve tentar isto com base numa leitura superficial e a partir de um círculo de pensamento não-fenomenológico, sem ser desautorizado por todos os que entendem efetivamente" (HUSSERL, 1984, p. 535). 
Delineados os possíveis obstáculos metódicos e expostas as melhores alternativas para enfrentá-los, Husserl dedica-se na seqüência à explicitação das peculiaridades inerentes à apreensão de essências e de suas conexões essenciais. Dinâmica apreensiva que deve privilegiar o modo de doação das vivências em detrimento dos dados estritos destas. Orientação metódica que não infirma o vínculo entre os respectivos níveis fenomenológicos das intuições individuais e de suas correspondentes apreensões essenciais. Em ambas as apreensões os níveis vão da obscuridade total, em que não há propriamente doação, à clareza total, em que a proximidade doadora é plena, sem resto. Reafirma-se assim o intuicionismo husserliano: há sinonímia entre intuição e clareza, bem como entre não-intuição e obscuridade. Equivalência válida inclusive para as representações vazias, meramente simbólicas, inclusão que amplia o campo semântico da noção de apreensibilidade (Erfassheit), aproximando-a do sentido da noção de disponibilidade (Bereitschaft). Decorre daí a segmentação husserliana entre graus autênticos e inautênticos de clareza ou obscuridade apreensivas. No plano autêntico de clarificação opera-se com a intuibilidade (Anschaulichkeit) em seus inumeráveis graus. No plano inautêntico de clarificação ultrapassam-se os limites da intuibilidade, em complexos apreensivos cuja clarificação depende de duas operações complementares: trazer da vacuidade à intuição e depois intensificar o intuído. É no plano inautêntico que se processa em regra o método de clarificação. A passagem do obscuro ao intuível e à efetivação consequente dos diferentes graus deste ocorre de modo progressivo e envolve a determinação paulatina dos vários elementos implicados nos horizontes intencionais constitutivos de cada ato de apreensão essencial.

Eis o contexto teórico inicial em que se insere o texto de Husserl citado no começo deste artigo sobre o papel da ficção na fenomenologia. Trama que, associada ao conteúdo do parágrafo de que a citação é extraída e dos parágrafos subsequentes, mostra-se decisiva à compreensão dos motivos husserlianos para caracterizar sua defesa do privilégio metódico da ficção como um discurso paradoxal, plurívoco e, desde que considerado isoladamente, favorável ao ataque proveniente da atitude natural de conhecimento. Os motivos da paradoxalidade podem ser detectados na tessitura do próprio parágrafo 70 e decorrem da variação no estatuto funcional da presentação (Gegenwartigung) e da presentificação (Vergegenwartigung) no eixo da fenomenologia husserliana. De modo mais direto, o paradoxo, assumido pelo próprio autor, deriva da precedência fenomenológica da percepção num aspecto e da ficção noutro aspecto. Como expor, legitimar e, sobretudo, harmonizar os dois aspectos no cumprimento 
das tarefas descritivas fenomenológicas? Em estrita atitude transcendental, o privilégio da percepção ${ }^{7}$ concerne à originariedade (Originarität), ao passo que o privilégio da fantasia, mediante suas operações ficcionais, é a liberdade (Freiheit). Tanto os atos perceptivos quanto os atos de fantasia são intuitivos, ou seja, apreendem de modo pleno seus objetos visados. Contudo, esta intuitividade se processa de maneira diferente em cada caso: na percepção predomina a passividade, embora compensada pela presença originária do intuído; na fantasia predomina a atividade, embora marcada pela presença derivada do intuído. O exemplo da operação do geômetra, que Husserl associa, mutatis mutandis, à operação do fenomenólogo, ajuda a compreender a convivência dos primados perceptivo e ficcional:

$\mathrm{Na}$ fantasia ele (o geômetra) deve, certamente, tender para intuições claras, de que o desenho e o modelo o poupam. Mas no desenhar e no modelar efetivos ele fica preso, enquanto na fantasia ele tem a incomparável liberdade de remodelação arbitrária das figuras ficcionais, de percorrer as contínuas modificações das configurações possíveis, portanto, de engendrar inumeráveis novas formações, uma liberdade que primeiro lhe dá acesso às amplidões de possibilidades essenciais, com seus infinitos horizontes de conhecimentos essenciais (HUSSERL, 1976, p. 147).

Diante do exposto, torna-se plausível associar todo fenomenólogo à figura mitológica de Jano, cabendo-lhe conjugar num só exercício transcendental dois focos condutores da visada. Exigência paradoxal que Husserl parece considerar um desafio contínuo e necessário de sua concepção fenomenológica, nunca economizando esforços para descrevê-la e cumpri-la.

No tocante ao caráter multívoco do primado metódico da fantasia, ele decorre da variedade de âmbitos das vivências puras a serem descritas, cada um deles demandando adaptações no processo ficcional. Husserl é enfático ao distinguir o procedimento fenomenológico daquele inerente às disciplinas eidéticas de cunho matemático, tais como a geometria e a aritmética. Qualquer tentativa de transpor os modelos essenciais das matemáticas para as descrições fenomenológicas está previamente fadada ao fracasso. Considerando-se a fenomenologia uma ciência descritiva material de essência, não se lhe aplicam os parâmetros das ciências formais dedutivas de essência.

7 Husserl outorga uma vantagem à percepção interna em relação à percepção externa, por esta apresentar-se mais fluida, menos permeável às apreensões essenciais. 
É justamente tal caráter apenas descritivo e material que acarreta a plurivocidade da fantasia enquanto método fenomenológico privilegiado. Sendo sua função precípua descrever $\operatorname{concretos}^{8}$ eidéticos, a fantasia deve modular-se em consonância com seus campos de abordagem. Os graus de evidência essencial alcançados em regime transcendental acompanham tais variações. No caso das singularidades eidéticas, o alcance descritivo fenomenológico é restrito, circunscrevendo-se aos vários aspectos determinados e indeterminados apreendidos pelo fluxo puro das vivências. A fluidez dos concretos visados e de seus momentos abstratos impede, ipso facto, qualquer univocidade conceitual ou vocabular. Estabelecem-se assim limites importantes ao alcance do método fenomenológico, assumidos desde o começo por Husserl, embora não explorados pelo pensador em todas as suas implicações. Limites paulatinamente franqueados conforme se avança nos graus de especialidade: na modalidade do em geral (überhaupt), as descrições fenomenológicas alcançam seu nível máximo, com autonomia em relação às análises operadas nos graus inferiores. Em paralelo às amplas investigações no plano descritivo ainda permanece aberta a possibilidade de operações idealizantes, que complementam aquelas desprendendo-se da base intuitiva sem, contudo, abdicar da pureza e do rigor transcendentais.

Dimensão transcendental que, como disse Husserl, corre o risco de ser olvidada caso se tome a citação do parágrafo 70 de maneira isolada. Mais do que mera estratégia discursiva, o alerta husserliano em nota tem o papel de mostrar como é difícil manter as distinções necessárias entre os planos natural e transcendental, aqui relacionados à compreensão do processo ficcional. A fantasia não pode ser entendida como faculdade de um eu empírico. Embora as operações ficcionais tenham uma base psicológica, não é nesta que se deve buscar o sentido daquelas. Os estatutos do eu que fantasia, do objeto fantasiado e da relação que os vincula é estritamente intencional. A tarefa precípua do fenomenólogo que opera as variações ficcionais não equivale à do artista que exercita sua fantasia criadora para criar belas obras nos diversos campos estéticos. A diferença crucial concerne a que o primeiro opera em regime de redução, sem depender dos componentes naturais, ao passo que o segundo opera em regime empírico, dependendo de tais componentes, embora os transmute artisticamente. As matérias-primas do fenomenólogo são as vivências puras, visadas de modo privilegiado na fantasia, cuja operação também transcorre numa perspectiva pura.

8 Conforme o sentido atribuído ao termo já nas Investigações lógicas.

Rev. Filos., Aurora, Curitiba, v. 22, n. 31, p. 347-378, jul./dez. 2010 
No âmbito fenomenológico, fantasiar significa ocupar-se de maneira peculiar com estruturas noético-noemáticas. Isto não implica, porém, a perda do âmbito natural parentesiado, mas antes a modificação de seu sentido, visando à apreensão essencial. É na modificação neutralizadora (Neutralitätsmodifikation) que a fantasia desempenha sua mais importante função metódica. Em regime de neutralidade, as estruturas noético-noemáticas escapam ao domínio estrito da razão, pois não mais se subordinam aos parâmetros de correção ou incorreção inerentes à consciência posicional em todas as suas formas presentadoras e presentificadoras. Além de cumprir o papel mais restrito de modo particular de consciência neutralizadora, sobretudo da presentificação posicional mnemônica (Erinnerung), a fantasia desfruta ainda de um alcance neutralizador mais amplo aplicável a todas as vivências puras. Tal ampliação, todavia, não equivale à modificação neutralizadora universal. Graças à similaridade no processo intencional, cabe indagar: como se distingue esta da modificação neutralizadora de fantasia? Na primeira ocorre a neutralização dos vários conteúdos intencionais presentados ou presentificados, ao passo que na última ocorre a neutralização dos próprios atos intencionais em que tais objetos intencionais se presentam ou se presentificam. A última implica um radical procedimento de reflexão em fantasia, no qual inclusive os atos ficcionais neutralizantes são neutralizados. Estatuto diferenciado que impede a sua reiteração, enquanto no caso da neutralização de fantasia não há limites iterativos.

Num nível ainda mais radical, a modificação neutralizadora universal estende sua operação parentesiadora ao conjunto de potencialidades dos atos intencionais, aos seus horizontes modulados pela atenção e inatenção transcendentais. Sob seu influxo vige dupla potencialidade: uma na consciência neutralizada e outra na consciência efetiva. O potencial, enquanto potencial, desfruta de uma efetividade que demanda ser neutralizada para que sejam apreendidas suas estruturas. Todas as vivências puras, inclusive as de fantasia nos diversos níveis neutralizadores, comportam fundos (Hintergründe) em que as diversas potencialidades podem ser visadas posicionalmente e neutralizadas. Instaura-se uma dinâmica descritiva de horizontes essenciais e contraessenciais, cujo resultado é a autoclarificação da consciência pura em sua infinita operação constitutiva. No caso dos objetos temporais, por exemplo, neutralizam-se seus respectivos horizontes retencionais e protencionais, ao passo que no caso dos objetos espaciais neutralizam-se seus horizontes de perfis potenciais, aplicando-se sucessivamente os ajustes necessários a todos os outros tipos de objetos intencionais. Diferenciações decisivas entre a dupla posicionalidade e suas respectivas neutralizações, demarcatórias de uma 
distinção universal na totalidade da operação constitutiva da consciência transcendental, ou seja, que abrange tanto as vivências puras de nível inferior, fundante (percepções, fantasias, memórias, etc) quanto as vivências puras de nível superior, fundado (afetos, volições, valorações, etc.), envolvendo as últimas um grau descritivo mais complexo.

A compreensão husserliana da modificação neutralizadora e dos temas a ela conexos despertou o interesse de importantes estudiosos, cabendo destacar dois deles: Eugen Fink e Maria Manuela Saraiva. Em seu ensaio intitulado Presentificação e imagem. Contribuições à fenomenologia da inefetividade, ${ }^{9}$ Eugen Fink procura expor e esclarecer o grave equívoco filosófico na compreensão dos conceitos presentes no título, vinculando-os justamente aos horizontes da temporalidade, que ele nomeia "depresentações" (Entgegenwärtigungen). ${ }^{10}$ A questão condutora é atinente à diferença entre o estatuto intencional das presentificações, mais diretamente da fantasia, e o estatuto intencional da consciência imaginativa (Bildbewusstsein), pouco explorada por Husserl na terceira seção de Idéias I. Considerando-se a consciência transcendental inicialmente a partir de suas vivências presentantes, nas quais ocorre a doação originária dos conteúdos intencionais, detecta-se nelas a propriedade essencial de modificação presentificadora que as converte noutras vivências, com outros sentidos intencionais, cujo estatuto de doação torna-se derivado. Nestas profundas conversões fenomenológicas, as depresentações

9 Publicado no Jahrbuch für Philosophie und phänomenologische Forschung (1930, p. 239309 , v. 10). O texto é precedido de um aviso do autor: "A presente pesquisa é um dos dois trabalhos premiados no concurso público organizado em maio de 1927 pela Faculdade de Filosofia da Universidade de Freiburg sobre o tema: 'Distinguir os fenômenos psíquicos compreendidos sob as expressões ambígüas de 'pensar-se como se', 'representar-se simplesmente algo', 'fantasiar' e submetê-los a uma pura análise fenomenológica'. Em novembro de 1929, a primeira parte, aqui impressa, foi apresentada como dissertação inaugural. $\mathrm{O}$ autor deve tanto às pesquisas fenomenológicas e à direção pessoal de seu mestre Edmund Husserl, tributando a seu trabalho a iniciativa de uma interrogação completamente provisória no horizonte dos problemas inaugurados por Husserl". Só esta primeira parte veio a lume. Apesar do reconhecimento declarado a Husserl, nota-se no modo global de abordagem do tema a influência incipiente, mas decisiva, de Heidegger. Para outros detalhes biográficos e filosóficos que permeiam a elaboração e publicação do ensaio, consultar o livro de Ronald Bruzina, Edmund Husserl \& Eugen Fink: beginnings and ends in Phenomenology, 1928-1938. sobretudo p. 7-10.

${ }^{10}$ Acompanha-se na tradução em português os exemplos da versão em francês (dé-présentations) do termo original, feita por Didier Franck, e da versão em inglês (depresenting-depresencing), feita por Ronald Bruzina. 
desempenham um papel nuclear, embora ainda não constituam propriamente atos fenomenologicamente determináveis e apreensíveis, instaurando antes simples intencionalidades passíveis de descrição pura. Para tanto, elas precisam passar da condição de latência essencial à condição de despertar no fluxo das vivências puras. Tal passagem ocorre ou mediante reflexão fenomenológica, mantendo suas imprecisão e obscuridade essenciais, ou sob o influxo direto das presentificações, determinando-se e clarificando-se nestas. $\mathrm{O}$ vínculo é o seguinte: as presentificações presentam as depresentações, cabendo às últimas fundar, desde seus respectivos âmbitos constitutivos, o processo intencional conjunto.

Embora os detalhes da dinâmica horizonte-temporal das presentificações, anunciados por Fink para a segunda parte do ensaio, não fossem publicadas, dispõe-se de relevantes indicações, no tocante à fantasia, no trecho divulgado do ensaio. A temporalidade do ego do mundo de fantasia difere daquela do ego do mundo das vivências puras atuais, ambas comportando horizontes retencionais e protencionais diversos. Tanto no caso de fantasias localizadas, em que o mundo ambiente efetivo ainda serve como motivação transcendental, ${ }^{11}$ quanto no caso das fantasias desvinculadas de qualquer referência ao mundo ambiente efetivo, o processo ficcional rompe com a temporalidade do presente dado para adentrar nos horizontes temporais fantásticos. Horizontalidade essencial que remete à questão do estatuto ontológico dos ficta. Novamente, Fink não se dedica diretamente a ela no trecho publicado do ensaio, fornecendo, porém, indicações úteis. Os ficta instauram-se no âmbito da inefetividade (Unwirklichkeit), da quase-presença, que não constitui mera negação ou mesmo privação da efetividade inerente às presentações, mas um desdobramento desta.

Torna-se capital distinguir fantasia e consciência imaginativa, bem como seus respectivos produtos intencionais: os ficta e as imagens. Distinção que Fink associa a dois tipos de modificação neutralizadora: do cumprimento e do teor. No primeiro tipo, o conjunto das vivências puras pode converter-se em simples aparência, sem qualquer resquício posicional, numa operação intencional que não pode ser repetida. A plena constituição do cumprimento remete apenas a noemas aparentes, desconectados de modificações atencionais estritas e desprovidas de implicações objetivantes genuínas. No segundo tipo, o ego constituinte opera uma modificação material do noema, que separa de modo abstrato no teor noemático os âmbitos efetivos e inefetivos codados e

${ }^{11}$ Fink dá o exemplo ultrapassado da fantasia "homem sobre a lua". 
apreensíveis enquanto momentos dependentes. $\mathrm{O}$ teor constitutivo ocorre por meio de atos mediais, que reservam um medium efetivo ao aparecimento do inefetivo e que podem ser sucessivamente repetidos.

A consciência imaginativa, motivada por produções humanas (fotografia, obra de arte, etc.) ou eventos naturais (reflexo na água, sombra, Fata Morgana, etc.), é entendida por Fink enquanto um tipo de ato medial. Nele conjugam-se intencionalmente o suporte efetivo da imagem e o mundo inefetivo imaginativo correspondente, comportando temporalidade e espacialidade peculiares. A inefetividade do mundo imaginativo equivale a momentos abstratos de efetividades determinadas pelos suportes materiais, que se encobrem através do ato medial. A cobertura (Verdecktheit) interliga numa só visada intencional mundo imaginativo e mundo do suporte, instaurando a janelaridade (Fensterhaftigkeit) da imagem. Considerado intencionalmente, o espectador da imagem se desdobra nas funções complementares de centro orientador do mundo imaginativo e sujeito deste mundo.

Tal como Fink, Saraiva, em sua obra A imaginação segundo Husserl, realça a analogia estabelecida por Husserl entre consciência imaginativa e fantasia. Restringe, porém, o alcance das exposições husserlianas concernentes à relação entre elas e, de um lado, a consciência estética; de outro lado, a consciência signitiva. No primeiro caso, Saraiva detecta excesso quando Husserl estende o processo presentificador por semelhança à consciência estética, em vez de limitá-la ao influxo da modificação neutralizadora. Tal pressuposto conduziria o pensador alemão a analisar a obra de arte a partir do espectador que a contempla e não do artista que a cria. Ao invés da concepção husserliana, as obras artísticas não presentificariam imitativamente a efetividade, mas as recriariam a partir de suas imanências esteticamente autossuficientes, sem necessidade estrita de remeter a transcendências efetivas que extrapolassem a mera aparência estética. No segundo caso, a intérprete diagnostica limitação na abordagem husserliana da relação entre imagem e signo, como ocorre na Primeira investigação lógica, em que o signo é relegado a segundo plano perante a expressão judicativa.

Saraiva procura pensar os vínculos e as distinções entre consciência imaginativa e fantasia a partir de seus processos fenomenológicos fundamentais: intenção, intuição, presentificação e neutralização. No plano intencional estrito, a estrutura da consciência imaginativa implica a interação do objetoimagem (Bildobjekt) com o sujeito-imagem (Bildsujet), ao passo que a estrutura da fantasia dispensa o primeiro componente e considera o segundo no modo constitutivamente produtivo. No tocante à intuição, embora diferindo nos graus de plenitude, consciência imaginativa e fantasia fazem ver seus 
objetos respectivos. Se à primeira pertencem atos intuitivos fundados, à segunda correspondem atos intuitivos fundantes. Os respectivos caracteres fundantes e fundados discriminam-se, de um lado, mediante os modos peculiares de apreensão, segundo os parâmetros do plano intencional estrito; de outro lado, mediante os modos característicos de preenchimento, com suas séries contínuas particulares de decepção ou cumprimento imaginativos. Quanto à presentificação, consciência imaginativa e fantasia partilham do mesmo estatuto de modificações reprodutivas de caráter retencional e protencional, privilegiando-se na primeira a dinâmica intencional do objeto presentante e na segunda o processo intencional do ato presentante, diferença de abordagem que dota a segunda de maior liberdade produtiva. Por fim, no que concerne à neutralização, procedimento orientado aos modos de crença, a consciência imaginativa desemboca na consciência estética, ao passo que a fantasia acarreta duas alterações complementares: uma enquanto vivência particular parentesiadora dos conteúdos imaginados e outra enquanto modificação universal parentesiadora de todas as vivências do eu puro, método indispensável visando à autodescrição sistemática deste em sua atividade constitutiva infinita.

\section{II}

Embora pertinentes em vários de seus pormenores, as interpretações de Fink e Saraiva sofrem de uma limitação decisiva: circunscrevem-se aos textos husserlianos disponíveis na época. Numa carta de $1^{\circ}$ de fevereiro de 1922 , endereçada a Natorp, Husserl afirma: "Encontro-me em situação bem pior que a sua, pois a maior parte de meu trabalho encontra-se em meus manuscritos (...). Tudo encontra-se em estágio de cristalização! Apesar de toda a tensão humanamente possível de minhas forças, talvez trabalhe apenas para minha obra póstuma" (HUSSERL, 1980, p. 31-32). ${ }^{12}$ Testemunho incisivo que implica a necessidade de referir-se às anotações privadas husserlianas concernentes ao

${ }^{12}$ Carta citada na Introdução do Editor, de Eduard Marbach, ao volume 23 da Husserliana. O trecho completo é o seguinte: "Encontro-me em situação bem pior que a sua, pois a maior parte de meu trabalho encontra-se em meus manuscritos. Quase maldigo minha inaptidão em saber deter-me, e o fato que me sejam dadas tão tarde, em parte somente agora, as idéias sistemáticas universais que no presente exigem também a reformulação de todas as minhas pesquisas específicas conduzidas até agora. Tudo encontra-se em estágio de cristalização! Apesar de toda a tensão humanamente possível de minhas forças, talvez trabalhe apenas para minha obra póstuma". 
vínculo metódico entre consciência imaginativa e fantasia, visando a aprofundar a análise do tema. Mostra-se decisivo explorar, em seus desdobramentos nucleares, o conteúdo do volume 23 da Husserliana. Nele podem-se acompanhar, de modo exemplar, as mudanças conceituais e argumentativas de Husserl, num nível ausente ou inexplorado de modo suficiente nas obras publicadas.

Cronologicamente, o primeiro texto remonta a $1898,{ }^{13}$ revelando a precoce ocupação husserliana com tais questões. O foco investigativo é a determinação das diferenças e similaridades entre consciência imaginativa e fantasia. ${ }^{14}$ Embora incipiente, a abordagem extrapola os quadros psicológicos, operando já num âmbito que se pode considerar fenomenológico, como atesta a afirmação do § 9: "Tomamos a aparição puramente por si e interrogamos o que a diferencia neste isolamento ideal" (HUSSERL, 1980, p. 127), retomada no $\S 16$, quando caracteriza a segmentação das representações como "puramente descritiva" (HUSSERL, 1980, p. 136). Em tal regime puro de consideração, cabe distinguir sobretudo as representações (Vorstellungen) perceptivas e imaginativas, segmentadas, respectivamente, segundo autopresentações da coisa (Sache) e presentificações em imagem (Bild), intuitividade (Anschaulichkeit) direta e indireta. As últimas se subdividem de acordo, sobretudo, com o grau de complexidade: as imaginativas em sentido estrito (mais complexas) e as fantásticas (mais simples).

Nas representações imaginativas estritas operam três componentes interligados: imagem física, objeto-imagem e sujeito-imagem. Nas representações fantásticas só os dois últimos componentes se conectam, faltando a base física suscitadora do processo imaginativo. Em ambas as representações, os respectivos conteúdos se constituem mediante atos próprios de apreensão objetivante, distintos daqueles inerentes aos outros tipos de representação. Relações objetivantes que se perfazem em duas direções, em dois momentos de um só ato que visa, separadas apenas no âmbito descritivo: a apreensão que objetiva numa imagem aparecente e a representação da coisa figurada em imagem. A primeira direção comporta dois desmembramentos, no modo fundantefundado: o ato presentante da imagem, que disponibiliza o objeto, embora em

13 Trata-se do apêndice I ao texto número 1 do volume 23 da Husserliana, datado do inverno de 1904/1905.

${ }^{14}$ É variada a terminologia husserliana empregue ao longo do texto para se referir aos dois tipos de vivência: o primeiro é designado, por exemplo, representação imaginativa, representação por imagem física; o segundo é denominado de representação fantástica, representação por imagem fantástica.

Rev. Filos., Aurora, Curitiba, v. 22, n. 31, p. 347-378, jul./dez. 2010 
si não seja objetal, e a consciência da representação imaginativa, que constitui o voltar-se visando ao objeto, o efetivar-se de sua função representativa. Tal papel representativo é análogo à presentação indireta na representação perceptiva, pois em ambos os casos inclusive as determinidades (Bestimmheiten) não aparecentes são apreendidas de modo mediato, através de cadeias convergentes fundadas nas determinidades aparecentes.

Considerando-se tais distinções em seu conjunto, detecta-se, finalmente, tanto nas representações imaginativas estritas quanto nas representações fantásticas, quatro componentes básicos a serem descritos em suas operações próprias: atos de apreensão presentativa em que o objeto imaginado ou fantasiado aparece, atos de apreensão representativa em que o objeto imaginado ou fantasiado exerce sua função de representante-imagem, atos que visam ao ser-objeto imaginado ou fantasiado, conteúdos sensíveis. Propriedades comuns a ambos os tipos de representações, mas que comportam também importantes diferenças, sendo justamente no último grupo de componentes que elas se tornam decisivas. Embora partilhem dos mesmos caracteres de ato, os dois tipos de representação discriminam-se no tocante ao fundamento de apreensão (Auffassungsgrunde) a partir do qual cada tipo se constitui. A imagem física, enquanto objeto efetivo inerente ao campo perceptivo, funciona como suscitador, ponto de partida e de passagem das representações imaginativas estritas. A imagem fantástica exclui qualquer vínculo instaurador com a efetividade, com o campo perceptivo possível. No primeiro caso, o conteúdo sensível presentante diz respeito às sensações; no segundo caso, refere-se aos fantasmas.

No intuito de esclarecer as distinções entre sensações e fantasmas, enquanto conteúdos mediante os quais objetos aparecem, Husserl entende necessário investigar as diferenças internas e externas entre aparições (Erscheinungen) perceptivas e fantásticas. O procedimento husserliano consiste em analisar várias opções explicativas (classes, intensidade, fluência, gênero) sem avançar conclusões, numa postura questionante que não parece derivar apenas do caráter lacunar do texto publicado postumamente, mas de hesitações teóricas profundas diante do que o próprio filósofo designa de "melindrosa questão descritiva" (HUSSERL, 1980, p. 124).

Questão condutora do texto de $1904-1905,{ }^{15}$ no qual o filósofo confessa pretender

15 Texto número 1 do volume 23 da Husserliana, que contém a terceira parte das lições do semestre de inverno de 1904-1905 sobre "Tópicos principais da fenomenologia e da teoria do conhecimento". 
avançar no trabalho paulatinamente e com a máxima cautela possível. Pois se a análise parece simples primeiramente, são tão grandes as dificuldades que se põem depois e que, gradativamente, exigem muitas modificações no que antes foi admitido e muitas novas distinções no que antes se tomou por simples (HUSSERL, 1980, p. 17-18).

O primeiro passo consiste em ligar a representação imaginativa estrita $^{16}$ e a representação fantástica, de modo similar ao texto de 1898. Mantémse, porém, a atribuição de maior complexidade à primeira, graças a ela incluir o componente suscitador físico, faltante na segunda. Não se descarta, contudo, a função desse, desempenhada, na representação fantástica, pela imagem espiritual (geistige Bild) enquanto simples ficção. Nos dois tipos de representação imaginativa, sensações e fantasmas funcionam respectivamente enquanto fundamento da consciência imaginativa em geral, da

consciência objetivante, a apreensão que dota de sentido o conteúdo, lhe confere uma relação objetal, aquela que, a partir do ser-aí (Dasein) cego do conteúdo, faz que ocorra o apreender objetal deste como isto ou aquilo, o representar de algo com ele, o visar não este conteúdo, mas algo por seu intermédio (HUSSERL, 1980, p. 22).

Tal apreensão tem como resultado o objeto-imagem representante, que, considerado isoladamente, ainda não constitui uma imagem no sentido próprio, sendo necessária para tanto uma segunda apreensão constitutiva de um segundo objeto, o sujeito-imagem. Nexos de apreensão similares aos vigentes na relação entre palavra e signo, na qual só a segunda apreensão dota a palavra de caráter significante autêntico. ${ }^{17}$

Objeto-imagem e sujeito-imagem, bem como seus correspondentes objetos, não se vinculam segundo os parâmetros de uma consciência relacional comparativa. Não há no processo imaginativo duas representações separadas que apenas se aglutinam, mas uma consciência relacional de fundação, cuja primeira apreensão serve de base presentativa, não sendo a segunda apreensão uma nova presentação, pois não remanescem conteúdos sensíveis para fundá-la. O regime vinculante das duas apreensões é de integração, de fusão

${ }^{16}$ Denominada agora de "imaginação física" (physische Imagination).

${ }^{17}$ Os vínculos entre função imanente e função simbólica da consciência imaginativa em geral são expostos com maiores detalhes nos parágrafos 15,16 e 40 do texto. 
instauradora, segmentando-se só numa abordagem descritiva. Para a análise pura, há várias intenções possíveis, cada uma com suas visadas peculiares em acordo com os componentes privilegiados. Caso se focalize o campo relacional das apreensões, detecta-se que o nexo entre elas é de dependência ou independência, exemplificado pelos bonecos de cera, cujos conteúdos sensíveis podem conduzir a uma apreensão perceptiva ou a uma apreensão imaginativa estrita, indicando o caráter independente da última em relação à apreensão dependente do sujeito-imagem nela fundada.

No tocante às relações entre objetos-imagem e conteúdos sensíveis, cada caso de representação imaginativa comporta implicações analíticas peculiares. Na consciência imaginativa estrita, o objeto-imagem aparece enquanto um nada de efetividade em conflito com o presente efetivo atual. Um não-agora (Nicht-Jetzt) aparece no agora. Conflito que se radicaliza quando, a partir da mesma base sensível, podem ocorrer duas apreensões perceptivas divergentes, sendo uma delas aparência sensível (Sinnesschein), como nos exemplos da imagem refletida do bastão rompido na água ou do boneco de cera. Caráter conflitual que se suprime no caso da consciência fantástica, pois nela os conteúdos de apreensão não operam simultaneamente como conteúdos perceptivos próprios ou impróprios. Há separação total entre campo fantástico e campo perceptivo.

Tal separação suscita a pergunta acerca do estatuto de aparecimento da imagem fantástica. Na fantasia falta o fictum enquanto objeto aparente de percepção, acarretando a ausência de conflito explícito entre campo perceptivo e campo fantástico. A coisa fantástica aparece num mundo inteiramente separado daquele do presente atual. Tomada exatamente como aparece na fantasia, a coisa fantástica escapa a todos os parâmetros perceptivos. Na essência da fantasia encontra-se a consciência-de-não-presentidade (NichtgegenwärtigkeitsBewusstsein), sendo apenas no modo sucessivo que percebido e fantasiado podem aparecer. O encadeamento das aparições fundadas em sensações e fantasmas não é unitário: as duas podem ligar-se por nexos intencionais, mas não por nexos de copertença intencional recíproca instauradora de unidades intuitivas.

Delimitação válida também para o nexo entre campo perceptivo e campo fantástico, que não podem ser intuídos em conjunto: a visada em um implica a supressão atual do outro, e vice-versa. Vigora entre eles a síntese de conflito (Synthesis des Widerstreits), que conduz à unidade sintética as partes equivalentes dos campos, nos modos da convergência ou da divergência, sem remeter a unidades de aparição. A passagem dum campo a outro implica uma descontinuidade objetal, modalizada segundo os tipos de consciência imaginativa 
em geral. No caso da consciência imaginativa baseada em sensações, o processo ocorre mediante apreensões perceptivas constitutivas de um presente no qual sensação vale como imagem de algo não-presente e também como selo de realidade. No caso da consciência fantástica, o fantasma se dá num caráter de irrealidade, de não-presença, cabendo à reflexão indireta conferir-lhe um presente adquirido. Modalizações em que sensações e fantasmas vigoram a partir de uma diferença fenomenológica originária: presentação e presentificação.

Embora os elementos dessa diferença sejam mencionados e abordados ao longo dos textos de 1898 e de 1905 e de seus anexos, ainda falta neles uma compreensão e uma exposição adequadas do âmbito fenomenológico radical a que tais elementos remetem: a consciência do tempo. ${ }^{18}$ Demanda que começa a ser atendida justamente no texto número 2, cuja datação é imprecisa.

${ }_{18}$ Pedro Alves aponta e discute esta lacuna no capítulo II de seu livro Subjectividade e tempo na fenomenologia de Husserl. Ele considera que "o texto de 1898 e as Investigações Lógicas no seu todo acabam por sucumbir à tendência para interpretar a fantasia a partir do fio condutor da Bildbewusstsein" (ALVES, 2003, p. 65). Com tal fio condutor, Husserl transforma uma duplicidade intrínseca à representação da fantasia em dois objetos separados: um Bildobjekt enquanto momento presentativo e um Bildsujet enquanto consciência intuitiva imprópria da coisa visada. "É o bom entendimento deste ponto que causa uma dificuldade extraordinária no texto de 1898. A razão última desse facto está na omissão do problema do tempo como fio condutor e na sua deficiente substituição pela oposição entre consciência de coisa e consciência de imagem" (ALVES, 2003, p. 67). Escolha teórica husserliana de graves consequências: "Há, no entanto, um pesado preço a pagar por esta determinação da essência da fantasia a partir do fio condutor da consciência de imagem. Falamos particularmente da catastrófica teoria dos 'fantasmas', como conteúdos primários específicos de apreensão da fantasia" (ALVES, 2003, p. 70). O ponto mais desconcertante da insuficiente abordagem husserliana concerne, entretanto, à subordinação da consciência temporal à consciência de imagem: "Na verdade, quando Husserl se abeira dos problemas específicos da consciência do tempo a partir da oposição reitora entre o par Wahrnehmung-Gegenwärtigung e o par Phantasie-Vergegenwärtigung, a sua decisão de base consiste justamente em interpretar 'a própria temporalidade como uma forma de consciência figurativa"” (ALVES, 2003, p. 77). O próprio Husserl se dá conta dos impasses do modelo da consciência de imagem e o abandona gradativamente, em favor do modelo da consciência do tempo e, mais especificamente, da memória enquanto consciência reprodutiva: "O modelo do Bildbewusstsein para a determinação da essência da presentificação significava, assim, a presença recalcitrante de um suposto naturalista no interior da fenomenologia incipiente. A progressão de Husserl entre 1898 e os anos de 1907-1911, a propósito dos actos intuitivos de 'grau mais baixo', é precisamente o lugar onde se produz a libertação da fenomenologia relativamente à sua primeira apercepção naturalística da consciência. Essa libertação exprime-se, tecnicamente, no afastamento do tema da Bildbewusstsein e na sua substituição pelo da Reproduktion" (ALVES, 2003, p. 101).

Rev. Filos., Aurora, Curitiba, v. 22, n. 31, p. 347-378, jul./dez. 2010 
Nele, Husserl aborda a reflexão na fantasia, numa postura questionante voltada a explorar as várias alternativas de compreensão do tema. A possibilidade legítima de atentar não ao conteúdo objetal da fantasia, mas a seu aparecer, a seu ser-fantasiado, concerne à essência do processo fantástico. Reflexão, no sentido lato, que se modaliza segundo alguns parâmetros principais: percepção de fantasia, fantasia de percepção e fantasia de fantasia. ${ }^{19}$ No primeiro caso, o ato fantástico é visado pela atenção perceptiva; no segundo caso, o ato perceptivo é visado pela atenção fantástica; no terceiro caso, o próprio ato fantástico é visado pela atenção fantástica. Em tais casos de modificação reflexiva, o regime de instauração corresponde ao quase (gleichsam, quasi), ao como-se (als ob), pela conversão da visada primitiva em objeto analisado em suas estruturas. Modificação multiplamente modalizada que recebe a designação de fantasia interna (innere Phantasie). Cada modalização consiste num pôr (Stellen) objetual que lhe é inerente em concordância aos componentes estruturais da quaseconsciência equivalente.

Tanto na modificação fantástica simples quanto em suas modalidades mais complexas, o processo intencional instaura-se segundo nexos temporais. O conteúdo modificado fantasticamente dá-se numa distensão temporal cujo limite é o agora da presentificação fantástica. Encadeamentos temporais abordados por Husserl sobretudo a partir da análise do vínculo entre fantasia e memória (Erinnerung). A memória é um ato fundado na fantasia simples, ato cujo caráter não é imaginativo, mas impressional. À simples percepção externa de algo, opõe-se a simples fantasia pura deste algo. A memória constitui uma nova apreensão que põe o algo fantasiado como passado, como representificado em relação ao presente atual. A principal diferença entre memória e fantasia decorre da qualidade da crença vigente em cada caso: no primeiro, consciência não-modificada e crença impressional no agora-passado; na segunda, consciência modificada pela ausência de crença e vigência de inatualidade.

Como na relação entre percepção e fantasia, no vínculo entre memória e fantasia também são possíveis várias modalizações: memória de fantasia, memória de memória, fantasia de memória. Idealiter, toda vivência admite várias modificações intencionais. Tendo como base cada indivíduo considerado noeticamente, detecta-se que ele possui uma essência concreta, ou seja, um conteúdo concreto que singulariza o geral. O indivíduo é essência individual numa diferença que para cada indivíduo é outra, irrepetível,

${ }^{19}$ Husserl emprega, de maneira equívoca, os termos Imagination e Einbildung no sentido estrito de fantasia.

Rev. Filos., Aurora, Curitiba, v. 22, n. 31, p. 347-378, jul./dez. 2010 
inespecificável. Destacam-se a situação temporal (Zeitliche Lage) e a situação espacial (Raumlage). Situações que, como todas as determinações, referemse a conceitos e essências gerais, que apagam as diferenças de cada situação determinada. No caso, porém, das situações temporais e espaciais, além da conformação geral, seus gêneros respectivos admitem diferenciações individuais. Há uma diferença de conteúdo, enquanto essência individual, e de forma, enquanto determinação individualizante predicável do objeto, que não é predicado como momento de essência correspondente.

Toda consciência doadora individual é intuitiva, seja no modo da efetividade, seja no modo da quase-efetividade. A originariedade de doação ocorre na percepção. Um individual é percebido quando se dá na efetividade originária do presente ou nos horizontes perceptivos originários da retenção e da protenção. Estes outros modos de doação intuitiva concernem ao caráter reprodutivo da rememória (Wiedererinnerung), em que o individual dado é reatualizado desde sua condição integralmente passada, e da promemória (Vorerinnerung), em que o individual é visado no modo da expectativa desde sua condição integralmente passada. Na fantasia, a relação com a efetividade é indireta, e se divide no modo perceptivo (consciência imaginativa estrita) e no modo reprodutivo (fantasia simples), que não pode ser confundido com o modo reprodutivo não-modificado da memória. A consciência fantástica é uma consciência modificada, na qual algo é dado como sendo, tendo-sido ou a ser em experiência, mas cuja efetividade não concerne estritamente ao ser passado, presente ou futuro.

Tal característica essencial da fantasia vincula-a aos temas da possibilidade e da neutralidade. $\mathrm{O}$ fantasiado é quase experienciado como isto ou aquilo, com sentido mais ou menos determinado. A experiência em fantasia é ela própria experiência possível. Uma possibilidade pura deve excluir a coposição de qualquer efetividade individual, constituindo-se exclusivamente mediante uma quase-experiência fantástica. A iteração das possibilidades se dá por quase-síntese, enquanto a formação de novas possibilidades ocorre mediante quase-conflito. Fantasias equivalentes em conteúdo comportam um regime de indeterminação temporal que impede constatar se são simultâneas ou não, se presentificam o mesmo objeto ou não. A fantasia pura modifica toda crença, não a modaliza numa nova crença de ser modalizada e, assim procedendo, instaura de modo contínuo possibilidades puras.

Campo de possibilidades que remete ao nexo entre fantasia e neutralidade, tratado na terceira seção de Idéias $P^{20}$ e retomado no texto número

${ }^{20}$ Conforme exposto e discutido no início deste artigo. 
20 do volume 23 da Husserliana. ${ }^{21}$ No exercício fantástico detectam-se duas epochés ou neutralizações: a primeira inerente à fantasia enquanto modificação dos outros modos de apreensão objetal, a segunda concernente à mudança de atitude mediante a instauração de um eu posicional sobre o eu neutro, cumprindo aquele a função de espectador desinteressado. Sob o regime do eu não engajado invalida-se qualquer crença, qualquer atitude em relação aos próprios conteúdos fantásticos estruturados segundo os parâmetros do como se. Husserl denomina a visada do eu desinteressado de simples pensamento (blosser Gedanke), por abster-se completamente de toda consideração quanto ao estatuto de ser ou não-ser dos objetos fantasiados. Embora desfrutem de similaridade, modificações reprodutivas de fantasia e abstenções fantásticas desempenham papéis distintos no processo intencional.

\section{III}

Vários intérpretes contemporâneos dedicaram-se à análise dos textos contidos no volume 23 da Husserliana, bem como trataram em geral dos temas husserlianos da consciência imaginativa e da fantasia. Angela Ales Bello (2003), em seu artigo O símbolo na experiência sacro-religiosa: uma análise fenomenológica, investiga a importância do conhecimento simbólico à compreensão da experiência do divino. Descrever a função simbólica implica circunscrevê-la em relação aos vários modos imaginativos e mnemônicos de consciência. Considerando-se a sensibilidade religiosa como abertura constitutiva do humano a algo que o transcende, a partir das manifestações sacras materiais arcaicas, detecta-se uma combinação sui generis do hilético e do noético em que predomina um realismo simbólico estranho à apreensão simbólica contemporânea dos objetos sacros. Na mentalidade arcaica, o símbolo religioso constituía-se pela presença, propiciando uma comunicação imediata com o numinoso. Na mentalidade cristã nascente começa a esboçar-se o vínculo símbolo-presença, embora o hilético mantenha seu privilégio no âmbito sacramental. Importância da dimensão simbólica que se amplia com o decorrer dos séculos, sem, contudo, anular o papel da presença na plena manifestação do objeto religioso enquanto instrumento da experiência numinosa.

Valeria Ghiron (2003), em seu texto $A$ noção husserliana de Bildbewusstsein e Einfühlung em vista de uma teoria do teatro, investiga as

${ }^{21}$ Cuja datação remonta a 1921-1924. 
implicações estéticas do texto número 18 da Husserliana 23, mais detidamente da fruição teatral. A autora defende que o modelo de compreensão da consciência imaginativa mostra-se aplicável, mutatis mutandis, à descrição estrutural da relação entre o espectador e os vários componentes do espetáculo teatral. A atividade dos atores no palco cria fictos puramente perceptivos, sem posição efetiva, mas enquanto meros caracteres do como-se. Fictos animados pela empatia estabelecida entre espectadores e atores no âmbito teatral, produzida em regime analógico, graças à irredutível opacidade do vínculo empático. Esquema descritivo husserliano que dá conta da dinâmica do teatro convencional, mas não é aplicável tout court ao teatro de vanguarda, transformador do próprio contexto espetacular a partir de uma dimensão metalinguística que demanda outras abordagens compreensivas.

Carmelo Calì, no trabalho Indeterminabilidade e identidade nos mundos ficcionais, trata da questão da identidade dos objetos fantásticos em seus diferentes âmbitos de manifestação. $\mathrm{O}$ autor considera que as condições de determinação e identificação válidas para os objetos materiais, pautadas por parâmetros espaço-temporais e por estruturas horizontais a eles inerentes, não se aplicam aos objetos fantásticos. O mundo perceptivo é um sistema infinitamente determinável, no qual toda variação é decidível a priori a partir do vínculo entre a experiência atual e seus horizontes concordantes ou discordantes. Vínculo faltante no mundo fantástico, pois o que ultrapassa seus limites permanece indeterminado, sendo toda determinação posterior de um objeto fantástico atualmente dado marcada pela arbitrariedade das possibilidades inscritas no horizonte fantástico que se fecha sobre si.

Diversos outros artigos e livros recentes abordam de maneira fecunda os temas husserlianos da consciência imaginativa e da fantasia, ${ }^{22}$ destacando-se aqui a exposição e debate do livro Fenomenologia e imaginação em Husserl e Heidegger, de Brian Elliott, pela abordagem sistemática dos temas mencionados no conjunto da obra de Husserl e, sobretudo, pelo papel de destaque a eles outorgado em vista de uma compreensão do método fenomenológico

${ }^{22}$ Apresentam-se a seguir os títulos e autores de alguns deles: Consciência inconsciente em Husserl e Freud, de Rudolf Bernet; Husserl e Freud: tempo, memória e o inconsciente, de Aaaron L. Mishara; Descrição e percepção plástica: uma crítica da teoria da consciência pictórica de Husserl (2007b) e Da afetividade à subjetividade (2007a), de Christian Lotz; Sobre auto-afecção fantasmática na apercepção tipificante e na consciência interna do tempo, de Dieter Lohmar; "Mas o relâmpago na noite de tempestade?"-Fenomenologia de um limite da percepção, de Paul Ducros; O espaçamento da imaginação: Husserl e a fenomenologia da imaginação, de John Sallis.

Rev. Filos., Aurora, Curitiba, v. 22, n. 31, p. 347-378, jul./dez. 2010 
husserliano. Elliott emprega e comenta desde textos husserlianos anteriores às Investigações lógicas até as anotações particulares publicadas postumamente, adotando como fio condutor expositivo o paralelo entre a perspectiva fenomenológica husserliana e a perspectiva crítica kantiana.

Elliott interpreta inicialmente alguns ensaios husserlianos redigidos na década de 1890. No artigo Estudos psicológicos de lógica elementar, de 1894, o comentador foca a distinção husserliana entre representações próprias e impróprias, caracterizando-se as primeiras pela intuitividade e as segundas pela mera representação - distinção em cuja vigência Husserl encontraria dificuldades para enquadrar as representações imaginativas num dos tipos estabelecidos, pois elas operam num âmbito diferente tanto da intuição quanto da significação estritamente consideradas. Hesitação husserliana legada do oscilar kantiano em discriminar os limites da esfera imaginativa entre sensibilidade e entendimento. Vacilação decorrente em larga medida da concepção estática de ambos os polos envolvidos, que os converte em classes divergentes de objetos visados, num oniabrangente panorama de intuições próprias e representações impróprias, ligadas temporalmente mediante a posição fixa da impressão originária.

Interpretando outro texto desta época, ${ }^{23}$ agora de 1893, o comentador destaca o interesse husserliano em compreender a unidade e a continuidade do dinamismo mental a partir do exemplo que se tornará paradigmático: a audição de uma melodia. Atentando à sequência da presentação melódica, Husserl reconhece um sentido restrito e outro amplo de intuição, o primeiro vinculado ao momento presentante e o segundo ligado ao ato atencional perdurante. Dado o caráter temporal do processo intuitivo da melodia, deve-se reconhecer neste vivências de recognição em cuja base se constituem a unidade e a continuidade do som melódico. Processo recognitivo vigente, mutatis mutandis, em toda presentação objetiva. O comentador ressalta que “para Husserl, o 'sentido' do dado é sempre informado por um 'pré-sentido' intencional” (ELLIOTT, 2005, p. 12), instaurado já no nível da sensibilidade e não, como defendia Kant, apenas no nível do puro entendimento. A verdade intuitiva conecta o visado como conjunto estrutural e sua autopresentação preenchente.

Embora Husserl tenha agregado uma perspectiva dinâmica ao considerar o estatuto da imaginação no segundo texto analisado, permanece a dificuldade de conciliar seus componentes representativos e intuitivos. Desafio retomado no ensaio de 1894 sobre Objetos intencionais, perpassado pela

${ }^{23}$ Intuição e representação, intenção e preenchimento.

Rev. Filos., Aurora, Curitiba, v. 22, n. 31, p. 347-378, jul./dez. 2010 
polêmica com Twardowski. Guiado pela questão das presentações sem objeto e reprovando a teoria pictórica da consciência, Husserl defende que na perspectiva intencional o importante são os modos de presentação, em vez dos objetos presentados, privilegiando-se o como em relação ao que. Porém, as implicações de tal diferença não são devidamente incorporadas à abordagem husserliana da imaginação, podendo assim transformar esta em chave compreensiva de todas as presentações impróprias. Tal lacuna se deve à concepção husserliana da unidade ideal entre intenção e intuição, verdade e ser, apesar da heterogeneidade de suas vigências intencionais respectivas. Impasses inerentes aos primeiros textos husserlianos, que incitam o intérprete a colocar duas questões relevantes quanto ao estatuto husserliano da imaginação:

Primeiro, se o ato intencional é uma presentação articulada de algo em sua ausência, como é esta realização básica da vida mental a ser caracterizada adiante? Segundo, o que produz e mantém a unidade do fluxo temporal de 'impressões' antes de todos os atos de reflexão que 'objetificam' o tempo vivo? (ELLIOTT, 2005, p. 18-19).

Para aquilatar os encaminhamentos husserlianos de tais questões, o comentador privilegia a análise da quinta e da sexta Investigações lógicas. Nelas, Husserl aprofunda a compreensão de que a consciência intencional não é produtiva, mas reveladora das estruturas de qualquer objetividade enquanto tal. Revelação na qual todo o processo imaginativo desempenha um papel metódico preponderante relativamente ao processo perceptivo, cabendo ao último a função de exemplaridade a partir da qual ocorre a ideação das essências gerais e de suas conexões ideais. Aos diferentes modos de visar a objetos possíveis correspondem diferentes modos de intuí-los, constatação que implica ampliar o âmbito do conceito de intuição, de maneira a incluir a imaginação como seu modo metodologicamente privilegiado. Além da intuição sensível, única aceita e explicitada por Kant, Husserl admite uma intuição categorial, que apreende em sua efetividade generalidades essenciais.

Elliott considera que, no intuito de melhorar a compreensão do papel da imaginação no processo intuitivo ampliado, Husserl explora os vínculos temporais que a instauram. O texto-chave refere-se ao curso de 1904-1905 sobre o tema, ministrado na universidade de Göttingen. $\mathrm{O}$ foco husserliano refere-se à consciência temporal, e não ao tempo objetivamente dado, não sendo aquela um mero agregado de momentos presentes, mas uma unidade sintética de caráter horizontal perpassada por impressões originárias, intenções e 
protenções. Após analisar os pormenores da exposição husserliana, o diagnóstico do comentador é severo:

As contradições internas e inconsistências da abordagem fenomenológica husserliana da consciência se acumulam: o colapso da distinção imaginação/ rememória; a tensão entre as noções distensão além do agora e contração atrás da presença pontual; as simultâneas atividade e passividade da subjetividade absoluta (ELLIOTT, 2005, p. 39).

São impasses cuja solução ou continuidade dependem justamente das investigações reunidas no volume 23 da Husserliana. Para o comentador, a principal contribuição do volume concerne à exploração da diferença entre consciência imaginativa e fantasia, destacando o caráter de estabilidade e identidade em que se processam as aparições da primeira e o caráter multiforme e instável das aparições da segunda. Temendo as consequências da fluidez plural da fantasia, Husserl adota como modelo metódico para a compreensão da imaginação em geral a unidade estática dos componentes da consciência imaginativa. Outro eixo teórico que perpassa o volume é o paralelismo entre percepção e fantasia, ambas preenchendo suas visadas intencionais de modo direto, seja mediante sensações, seja mediante fantasmas. Rede compreensiva que leva o intérprete a reforçar o diagnóstico desfavorável, sobretudo em relação ao texto principal do volume: "As lições de 1904-5, portanto, repetem o padrão de vacilação no tratamento de Husserl da imaginação identificado acima em relação aos primeiros escritos, particularmente às Investigações Lógicas" (ELLIOTT, 2005, p. 44).

Avaliação que se mostra mais auspiciosa no tocante aos textos do volume 23 da Husserliana próximos à publicação de Idéias I. Neles, o intérprete verifica importante ampliação do conceito de fantasia, não mais oposto ao conceito estrito de consciência imaginativa, mas compartilhando de seu estatuto de inatualidade presentativa, em especial nos modos de consciência estética e teórica, que empregam de maneira fecunda procedimentos fantásticos. A característica nuclear da fantasia, que a torna decisiva para o método fenomenológico, é a liberdade em relação à efetividade, compreensão motriz da tessitura conceitual e argumentativa de Idéias I, mas que se formula explicitamente, como se acompanhou na primeira parte deste artigo, no e em torno ao parágrafo 70. O comentador detecta, todavia, em tal tessitura limites teóricos intrínsecos à assunção plena da liberdade fantástica enquanto modelo metódico da fenomenologia. O primeiro refere-se ao caráter ambíguo do conceito 
de fenômeno, ora como âmbito extratemporal das estruturas possibilitadoras de qualquer evento, ora como âmbito em que algo é originalmente dado em seu caráter intencional. $\mathrm{O}$ segundo limite diz respeito à noção de impressão originária como base do processo descritivo temporal, marco de uma certa herança empiricista no projeto fenomenológico husserliano.

Abordagem direta dos componentes sensíveis que encaminha Husserl às análises fenomenológicas da síntese passiva, entendida como afetividade constituída. $\mathrm{O}$ eu responde aos estímulos que despertam sua atenção, cabendo à fenomenologia descrevê-los em suas estruturas puras, descrição que opera a partir de procedimentos genéticos, e não mais exclusivamente estáticos. Para o intérprete, tal passagem decisiva do estático ao genético implica inverter a prioridade da intuição sobre a intenção, da presença sobre a ausência. Numa perspectiva fenomenológica genética, ausência e intenção vazia desfrutam de prioridade no processo descritivo. No âmbito temporal, a impressão originária insere-se indissoluvelmente em horizontes de retenção e protenção. Vínculo enfatizado por Elliott: "Como Husserl compreende a consciência originária do tempo enquanto a estrutura sintética fundamental da vida consciente, segue-se do fundar da síntese temporal na síntese passiva ou imaginativa, que o sentido original da consciência intencional em Husserl é imaginativa" (ELLIOTT, 2005, p. 58).

Operando geneticamente, a fenomenologia husserliana mantém os conceitos anteriores, mas os compreende de modo mais radical. Um exemplo disto é o curso Psicologia fenomenológica, ${ }^{24}$ mormente no tocante à exposição da dinâmica do método ideatório, conduzido de maneira fantástica. Método desdobrado em quatro etapas: seleção de algo fatual como base para a variação eidética; processo de multiplicidade variacional; conexão unificadora a partir das coincidências; identificação seletiva a partir das congruências. Elliott defende uma certa correspondência metódica, mutatis mutandis, entre tais etapas e a divisão kantiana dos esquemas transcendentais, com a diferença de que para Kant os esquemas constituem um índice dos limites da razão pura no conhecimento da efetividade empírica, ao passo que para Husserl as várias fases do processo ideatório indicam a autonomia da razão em relação ao empírico e a sua aptidão infinita de transformar dados fatuais em possibilidades puras.

Repassando o conjunto dos textos husserlianos a partir do fio condutor da conexão entre imaginação/fantasia e método, Elliott considera que sua interpretação

${ }^{24}$ Curso do semestre de verão de 1925.

Rev. Filos., Aurora, Curitiba, v. 22, n. 31, p. 347-378, jul./dez. 2010 
apresentou Husserl como estando na sombra do legado kantiano e, assim, essencialmente envolvido num projeto filosófico de superar a dicotomia sensação-concepção que iniciou com o primeiro idealismo alemão. Embora as atuais análises de Husserl com freqüência sucedam em tal superação, sua auto-interpretação falha em resistir à atração de uma rígida divisão entre real e ideal. Em conseqüência, sua idéia de fenomenologia fica fatalmente comprometida por um preconceito racionalista (ELLIOTT, 2005, p. 66-67).

Na sequência do texto, o comentador entende que

Compreendendo a atividade racional como unificação de uma multiplicidade intuitiva e admitindo uma genuína função epistêmica à imaginação só na medida em que suas operações são racionalmente motivadas, Husserl oferece uma incessantemente parcial idéia de imaginação... Como resultado, o potencial positivo da apreensão imaginativa para compreender pluralidade e diferença sem subordinação à unidade conceitual, nunca é reconhecida por Husserl (ELLIOTT, 2005, p. 67).

Ficando a liberação de tais preconceitos, segundo o intérprete, a cargo da filosofia hermenêutica de Heidegger.

Citações que resumem as principais teses da leitura de Elliott, em consonância a um resgate global e minucioso do conjunto dos escritos husserlianos sobre o tema. Ampla interpretação conduzida pela denúncia da hesitação husserliana em esclarecer o estatuto metódico da consciência imaginativa e, sobretudo, da fantasia, motivada por orientações questionáveis de caráter sistemático: intransigente segmentação do real e do ideal; pressupostos racionalistas; inaptidão para pensar pluralidade e diferença. Acusações manifestadas, segundo diferentes perspectivas, por comentadores e pensadores passados e contemporâneos, sejam da vertente fenomenológica ou de outras matrizes filosóficas.

Discutir as várias facetas das restrições sistemáticas apontadas por Elliott extrapola os propósitos deste artigo. Circunscreve-se adiante, de maneira esquemática, a análise de tais acusações em seu vínculo à noção husserliana de fantasia. Não há dúvida de que a consciência fantástica passa por várias conformações teóricas ao longo do itinerário filosófico de Husserl, inclusive em seus últimos escritos públicos e privados. Não parece plausível defender uma versão definitiva para o tema, constatação válida, aliás, para os principais conceitos explorados pelo pensador alemão. Ele mesmo considerava sua investigação fenomenológica uma tarefa infinita de reflexão e descrição puras. 
Isto, entretanto, não equivale a negar constantes teóricas no tratamento da questão: entender a fantasia enquanto modo de consciência transcendental, e não facultativa; conceber a consciência fantástica como intuitiva em sentido ampliado e, ao mesmo tempo, visando ao objeto possível em sua ausência; dotar o processo fantástico do máximo grau de liberdade transcendental, a ponto de transformá-la em base do procedimento ideatório em geral; atribuir um caráter não posicional à visada fantástica.

Mesmo com tais convergências teóricas na concepção da fantasia, as dificuldades em estabelecer e expressar a contento o estatuto deste modo metodicamente privilegiado de consciência transcendental não devem ser imputadas ao pensador Husserl, mas sim à coisa mesma (die Sache selbst) em questão. No processo fantástico radical está em jogo a essência da própria constituição da consciência pura, movimento reflexivo em que esta intenta descrever sua própria instauração enquanto âmbito de efetivação de todas as possibilidades puras. ${ }^{25}$ Operar metodicamente com a fantasia transcendental equivale a adentrar na matriz anônima de toda produção (Leistung) de sentido, somente desde a qual todo mundo é enquanto tal. O obstáculo, que Husserl transformava em contínuo estímulo à investigação fenomenológica, encontrase em olhar o olho fantástico na sua operação em todos os níveis constitutivos. Parecem aplicar-se neste contexto as diretas indicações husserlianas expressas no parágrafo 13 das Meditações cartesianas, de que o trabalho fenomenológico compreende duas etapas: 1) abandonar-se diretamente aos dados da experiência transcendental; 2) efetuar uma crítica do alcance dos princípios desta experiência. Se na primeira etapa as conquistas husserlianas se mostram fecundas, sobretudo a partir da publicação póstuma das anotações privadas sobre os mais diversos âmbitos transcendentais, a segunda etapa, que não é uma mera crítica restritiva nos moldes kantianos, mas descritiva dos fundamentos fenomenológicos, os resultados se apresentam incipientes, demandando complementos que a investigação fenomenológica ulterior nem sempre explorou e explora como poderia.

Com base, porém, nas investidas críticas embrionárias de Husserl, já é possível dar conta das principais objeções de Elliott. Quanto à censura

${ }^{25}$ Em seu livro A evidência da possibilidade: a questão modal na fenomenologia de Husserl, Nuno Nabais afirma com precisão: "a novidade - e ao mesmo tempo o caráter paradoxal - do programa de uma descrição pura da possibilidade do conhecimento proposto por Husserl desde as Investigações Lógicas está na pretensão de tornar evidente o próprio campo transcendental" (NABAIS, 1998, p. 10).

Rev. Filos., Aurora, Curitiba, v. 22, n. 31, p. 347-378, jul./dez. 2010 
de divisão rígida entre real e ideal, o processo fantástico transcendental é, per si, uma refutação consistente, pois opera desde a dimensão integradora da intencionalidade. Sendo o cerne do projeto fenomenológico husserliano, desde seus primeiros textos, justamente abolir as várias dicotomias metafísicas, constitui impropriedade atribuir-lhe separações fixas entre fatos e essências. Efetividade e idealidade conjugam-se na instauração da totalidade dos objetos possíveis do mundo. Como se constatou anteriormente, o discurso husserliano é marcado por distinções, muitas vezes excessivas, mas todas elas devem ser consideradas no âmbito meramente descritivo, e não in re. A fantasia transcendental, enquanto radical modificação neutralizadora, vige num estatuto estritamente intencional, âmbito a partir do qual se pode conceber e expressar unidades e identidades, sejam elas reais ou ideais. Embora em certos trechos de seu texto ${ }^{26}$ Elliott defenda uma maior proximidade husserliana em relação à leitura tradicional de Aristóteles do que à de Platão no que concerne aos vínculos entre sensível e inteligível, no fim ele se contradiz ao entender a fenomenologia de Husserl segundo parâmetros da leitura platônica tradicionalmente difundida. A originalidade do programa filosófico husserliano encontra-se justamente na abertura do acesso e na ulterior descrição completa da experiência transcendental, que precede metodicamente toda investigação pontual sobre real e ideal. Aceitar a tese de Elliott significa, ipso facto, negar tal originalidade.

Quanto à objeção de preconceito racionalista, que ocasiona um enfoque unilateral da fantasia, sabe-se que do começo ao fim de sua obra Husserl atribuiu privilégio ao racional, ao teórico, como fonte de conhecimento. Transformar, todavia, tal privilégio em preconceito consiste em desconsiderar o alcance do sistema fenomenológico visado pelo pensador alemão. Novamente, Elliott se alinha à contestação feita por diversos comentadores e pensadores, sejam da tradição fenomenológica ou de perspectivas filosóficas divergentes. $\mathrm{O}$ ataque heideggeriano ao teórico em Husserl em favor do prático da cotidianeidade tornou-se paradigmático. Entretanto, no discurso husserliano racional significa estrutural, constitutivo, e não se opõe a prático, mas antes o funda. Operar de maneira racional equivale a descrever em sua pureza o conjunto das estruturas noético-noemáticas envolvidas em qualquer fenômeno, cabendo às estruturas fantásticas um papel metódico destacado, pelos motivos expostos neste artigo. A razão husserliana não é, como em Kant, a faculdade superior do conhecimento, mas o âmbito operatório de compreensão do fundamento de

${ }^{26}$ Conforme, entre outros, 2005, p. 26-32. 
tudo que se dá enquanto fenômeno. Racionalidade se confunde com humanidade entendida de maneira transcendental: todos os outros modos de ser do humano (práticos, axiológicos, estéticos, orgânicos, etc.) dependem do modo racional de unificação e identificação transcendentais para se tornarem algo com sentido. $\mathrm{O}$ enfoque racional não restringe a compreensão do processo fantástico; ao contrário, ele a amplia, colocando-se na raiz fenomenológica do próprio fantasiar. Se há algum preconceito nisso, ele só pode estar no alcance limitado da leitura de Elliott.

Por fim, cabe analisar a censura concernente à inaptidão da fenomenologia husserliana em dar conta da pluralidade e da diferença, que redundaria numa abordagem restrita da fantasia. É certo que Husserl distingue a fenomenologia das ciências de fatos ou positivas, ocupadas com os vários domínios objetuais. Sendo a fenomenologia uma ciência descritiva material de essências, tal como formulado em Idéias $I$, ela pressupõe que, no plano transcendental, o unitário e o idêntico fundam o plural e o diferente, cabendo à descrição fenomenológica dos dois últimos remeter-se às cadeias descritivas concernentes aos dois primeiros, em qualquer das estruturas noético-noemáticas. Caso a pluralidade e a diferença a que Elliott se refira digam respeito ao âmbito ôntico, objetual estrito, basta lembrar a precedência constitutiva do transcendental sobre o natural para que a reprovação se mostre inconsistente e não acarrete qualquer efeito restritivo na concepção husserliana de fantasia. Afastadas as consequências das três objeções, torna-se legítima, portanto, a confiança do pensador alemão no alcance metódico do processo fantástico, expressa com vigor no fim do parágrafo 70 de Idéias I.

\section{Referências}

ALES BELLO, A. Il simbolo nell'esperienza sacrale-religiosa: un'analisi fenomenologica. Memorandum, n. 5, p. 134-147, 2003.

ALVES, P. Subjectividade e tempo na fenomenologia hussserliana. Lisboa: Centro de Filosofia da Universidade de Lisboa, 2003.

BERNET, R. Unconscious consciousness in Husserl and Freud. Phenomenology and the Cognitive Sciences, n. 1, p. 327-351, 2002.

BRUZINA, R. Edmund Husserl \& Eugen Fink: beginnings and ends in Phenomenology, 1928-1938. New Haven \& London: Yale University Press, 2004. 
CALÌ, C. Indeterminabilità e identità nei mondi finzionali. Leitmotiv, n. 3, p. 143-150, 2003. DUCROS, P. Mais l'éclair dans la nuit de tempête? Phénoménologie d'une limite de la perception. Bulletin d'Analyse Phénoménologique, v. 3, n. 1, p. 3-53, 2007.

ELLIOTT, B. Phenomenology and imagination in Husserl and Heidegger. London; New York: Routledge, 2005.

FINK, E. De la Phénoménologie. Tradução do alemão de Didier Frank. Paris: Minuit, 1974.

GHIRON, V. Le nozioni husserliane di Bildbewußtsein e Einfühlung in vista di una teoria del teatro. Leitmotiv, n. 3, p. 105-111, 2003.

HUSSERL, E. Cartesianische meditationen und pariser vortrage. Den Haag, Netherlands: Martinus Nijhoff, 1973.

HUSSERL, E. Logische untersuchungen. zweiter band: untersuchungen zur phänomenologie und theorie der erkenntnis. Den Haag, Netherlands: Martinus Nijhoff, 1984.

HUSSERL, E. Ideen zu einer reinen Phänomenologie und phänomenologischen Philosophie Erstes Buch: allgemeine einführung in die reine phänomenologie. The Hague, Netherlands: Martinus Nijhoff, 1976.

HUSSERL, E. Phantasie, Bildbewusstsein, Erinnerung. Zur Phänomenologie der anschaulichen Vergegenwärtigungen. Texte aus dem Nachlass (1898-1925). Dordrecht: Kluwer, 1980.

HUSSERL, E. Idéias para uma fenomenologia pura e para uma filosofia fenomenológica: introdução geral à fenomenologia pura. Tradução de Márcio Suzuki. Aparecida, SP: Idéias e Letras, 2006.

HUSSERL, E. Idées directrices pour une phénoménologie et pour une philosophie phénoménologique. Tradução de Paul Ricoeur. Paris: Gallimard, 1950.

LOTZ, C. From affectivity to subjectivity: Husserl's phenomenology revisited. New York: Palgrave Macmillan, 2007a.

LOTZ, C. Depiction and plastic perception. A critique of Husserl's theory of picture consciousness. Continental Philosophy Review, n. 40, p. 171-185, $2007 \mathrm{~b}$.

LOHMAR, D. Über phantasmatische Selbstaffektion in der typisierenden apperzeption und im inneren Zeitbewusstsein. Leitmotiv, n. 3, p. 67-80, 2003. 
MISHARA, A. Husserl and Freud: time, memory and the unconscious. Husserl Studies, n. 7, p. 29-58, 1990.

NABAIS, N. A evidência da possibilidade-A questão modal na fenomenologia de Husserl. Lisboa: Relógio D’Água Editores, 1998.

SALLIS, J. L'espacement de l'imagination: Husserl et la phénoménologie de l'imagination. In: HUSSERL, E. Husserl-Collectif sous la direction de Eliane Escoubas et Marc Richir. Grenoble: Editions Jérome Millon, 1989. p. 65-88.

SARAIVA, M. M. A imaginação segundo Husserl. Tradução do francês por Isabel Támen e António Pedro Mesquita. Paris: Calouste Gulbenkian, 1994.

Recebido: 20/07/2010 Received: 07/20/2010

Aprovado: 21/09/2010 Approved: 09/21/2010 